\title{
LCMYB4, an unknown function transcription factor gene from sheepgrass, as a positive regulator of chilling and freezing tolerance in transgenic Arabidopsis
}

Xiaoxia $\mathrm{Li}^{1+}$, Junting $\mathrm{Jia}^{2 \dagger}$, Pincang Zhao ${ }^{3}$, Xiufang Guo ${ }^{1}$, Shuangyan Chen ${ }^{1}$, Dongmei Qi ${ }^{1}$, Liqin Cheng $^{1 *}$ and Gongshe Liu ${ }^{1 *}$

\begin{abstract}
Background: Sheepgrass (Leymus chinensis (Trin.) Tzvel) is a perennial forage grass that can survive extreme freezing winters $\left(-47.5^{\circ} \mathrm{C}\right)$ in China. In this study, we isolated an unknown function MYB transcription factor gene, LCMYB4, from sheepgrass. However, the function of LCMYB4 and its homologous genes has not been studied in other plants.

Results: The expression of the LCMYB4 gene was upregulated in response to cold induction, and the LCMYB4 fusion protein was localized in the nucleus, with transcriptional activation activity. Biological function analysis showed that compared with WT plants, LCMYB4-overexpressing Arabidopsis presented significantly increased chilling and freezing tolerance as evidenced by increased germination rate, survival rate, and seed setting rate under conditions of low temperature stress. Furthermore, LCMYB4-overexpressing plants showed increased soluble sugar content, leaf chlorophyll content and superoxide dismutase activity but decreased malondialdehyde (MDA) under chilling stress. Moreover, the expression of the CBF1, KIN1, KIN2 and RCI2A genes were significantly upregulated in transgenic plants with chilling treatment. These results suggest that $\angle C M Y B 4$ overexpression increased the soluble sugar content and cold-inducible gene expression and alleviated oxidative damage and membrane damage, resulting in enhanced cold resistance in transgenic plants. Interestingly, our results showed that the LcMYB4 protein interacts with fructose-1,6-bisphosphate aldolase protein1 (LCFBA1) and that the expression of the LCFBA1 gene was also upregulated during cold induction in sheepgrass, similar to LCMYB4.
\end{abstract}

Conclusion: Our findings suggest that LCMYB4 encodes MYB transcription factor that plays a positive regulatory role in cold stress.

Keywords: Sheepgrass, MYB transcriptional factor, Freezing tolerance, Chilling stress, Transgenic

\footnotetext{
* Correspondence: lqcheng@ibcas.ac.cn; liugs@ibcas.ac.cn

${ }^{+}$Xiaoxia Li and Junting Jia contributed equally to this work.

${ }^{1}$ Key Laboratory of Plant Resources, Institute of Botany, The Chinese Academy of Sciences, Beijing, China

Full list of author information is available at the end of the article
}

(C) The Author(s). 2020 Open Access This article is licensed under a Creative Commons Attribution 4.0 International License, which permits use, sharing, adaptation, distribution and reproduction in any medium or format, as long as you give appropriate credit to the original author(s) and the source, provide a link to the Creative Commons licence, and indicate if changes were made. The images or other third party material in this article are included in the article's Creative Commons licence, unless indicated otherwise in a credit line to the material. If material is not included in the article's Creative Commons licence and your intended use is not permitted by statutory regulation or exceeds the permitted use, you will need to obtain permission directly from the copyright holder. To view a copy of this licence, visit http://creativecommons.org/licenses/by/4.0/. The Creative Commons Public Domain Dedication waiver (http://creativecommons.org/publicdomain/zero/1.0/) applies to the data made available in this article, unless otherwise stated in a credit line to the data. 


\section{Background}

Chilling (low temperatures above $0{ }^{\circ} \mathrm{C}$ ) and freezing can adversely affect plant growth and reduce crop yield [1]. Under cold conditions, gene expression, enzyme activity, metabolism and cellular architecture are changed $[2,3]$, and many transcription factor (TF) genes are involved in the response and tolerance to cold stresses in plants [47]. Expression profiling of the model plant Arabidopsis treated with cold revealed that up to $20 \%$ of genes in the genome are regulated by cold [8]. The explicit mechanism of cold stress-induced transcription in plants is the C-repeat (CRT)-binding factor and/or dehydrationresponsive element (DRE) binding factor (CBF/DREB) cascade [9]. However, the expression levels of CBFs determine the expression of cold-responsive (COR) gene, which can encode cryoprotective proteins to enhance the freezing resistance of plant $[7,10,11]$. Previous studies have shown that the MYB15 can bind to the specific promoter elements of $C B F$ and inhibit the expression of $C B F s$, while the $C B F s$ can be induced by ICE1 (Inducer of $\mathrm{CBF}$ expression 1) and ICE1-like transcription factors [12-14]. The MYB family is one of the most important transcription factor (TF) families studied in plants [15]. The first plant MYB gene to be isolated, COLORED1 (C1), is related to anthocyanin synthesis in maize (Zea mays) kernels [16]. In contrast to animals, in plants, MYB TFs are involved in various developmental processes and many complex physiological processes, including regulating plant morphogenesis, growth and development, participating in plant stress response to biotic and abiotic stresses, and regulating plant primary and secondary metabolism processes [17-20]. MYB proteins contain highly conserved MYB DNA-binding domains, which can be divided into the following four types: MYB1R, R2R3-MYB, R1R2R3 MYB (MYB3R), and 4RMYB, based on the repeats of the MYB DNA-binding domains (one, two, three, and four), respectively [17].

Previous studies have shown that MYB TF family genes are involved in biotic and abiotic stress through the regulation of gene expression [5, 18, 21-23]. In Arabidopsis thaliana, AtMYB30, AtMYB60, and AtMYB96 are R2R3-MYBtype proteins and are involved in responses to drought stress and disease resistance [17]. However, AtMYB15 responds to cold and drought stress, and AtMYB108 is required for biotic and abiotic stress responses [24]. Studies on the functions of MYB proteins in rice (Oryza sativa) indicated that the overexpression of OsMYB3R-2, which is an R1R2R3 MYB gene, can increase tolerance to freezing, drought, and salt stress in transgenic Arabidopsis [23]. The OsMYBS3 gene can adapt short- and long-term cold stress and is a novel MYBS3-dependent pathway that confers cold tolerance in rice [25], and the OsMYB2 (R2R3-type MYB) gene enhances the salt, cold, and dehydration tolerance in rice [5]. Recent studies on Cichorium intybus have found that the R2R3-MYB TFs CiMYB5 and CiMYB3 regulate fructan 1-exohydrolase expression in response to abiotic stress and hormonal cues [21].

Sheepgrass (Leymus chinensis (Trin.) Tzvel) is a coldseason forage grass widely distributed on the eastern Eurasian steppe [26, 27], and the total area of sheepgrass grasslands in China is approximately $220,000 \mathrm{~km}^{2}$ [28]. Previous studies have showed that sheepgrass can grows well in drought condition( $<6 \%$ soil moisture), high salt stress $(600 \mathrm{mM} \mathrm{NaCl})$, and extreme freezing winters ($47.5^{\circ} \mathrm{C}$ ) [28-30]. We identified many stress-induced genes by sequencing the transcriptome of sheepgrass [27]. In our previous studies, we reported the functions of several novel genes and TF genes in sheepgrass [3133]. For example, LcSAIN1, LcSAIN2, and LcFIN2 were identified as novel genes from sheepgrass and were shown to enhance salt and cold stress tolerance in transgenic Arabidopsis and rice [28, 29, 34]. The ectopic expression of the R1-MYB transcription factor gene LcMYB1 from sheepgrass confers salt tolerance in transgenic Arabidopsis [35], and the overexpression of a novel cold-responsive transcript factor LcFIN1 improved freezing tolerance in transgenic Arabidopsis [30].

Here, we report for the first time that an unknown function MYB transcription factor gene, $L c M Y B 4$, from sheepgrass is involved in the cold stress response. Our results indicated that $L c M Y B 4$ plays an important positive role in transgenic Arabidopsis under chilling and freezing tolerance, and we are the first to find that the LcMYB4 protein can interact with the LcFBA1 protein in sheepgrass.

\section{Results}

\section{Molecular characterization analysis of LCMYB4 and} homologous genes

Here, a MYB TF gene, LcMYB4, from sheepgrass was cloned. The ORF of this gene is $828 \mathrm{bp}$ and encodes a predicted protein of 275 amino acids with a predicted molecular mass of $30.56 \mathrm{kDa}$, and an isoelectric point of 5.99 (GenBank accession no: MN327641). The SignalP 4.0 and TMHMM 2.0 server predicted showed that there was no signal peptide and transmembrane helix in the protein. Multiple sequence alignment analysis showed that the LcMYB4 protein had high similarity with 11 MYB homologous proteins in Hordeum vulgare, Aegilops tauschii, Triticum turgidum, Zea mays, Oryza sativa, Brachypodium, Arabidopsis thaliana, etc., and all the proteins had SANT/ MYB superfamily domains (Fig. 1a). The homology of LcMYB4 with $H$. vulgare was 95\% (Accession: BAJ91904.1), with $A$. tauschii was 94\% (Accession: XP_020178881.1), with $T$. turgidum was 94\% (VAI80123.1), with rice was 80\%(XP_015643724.1) and with Arabidopsis was 58\% (NP_ 568776.2) (Fig. 1b). However, the functions of LcMYB4 genes and their homologues have not been verified. 
A

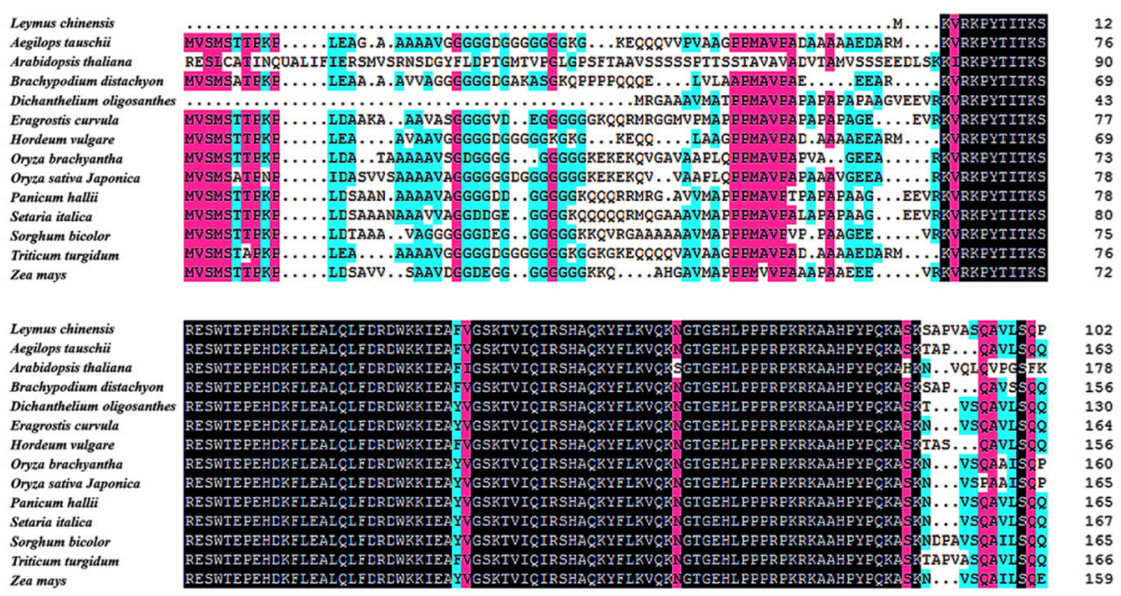

B

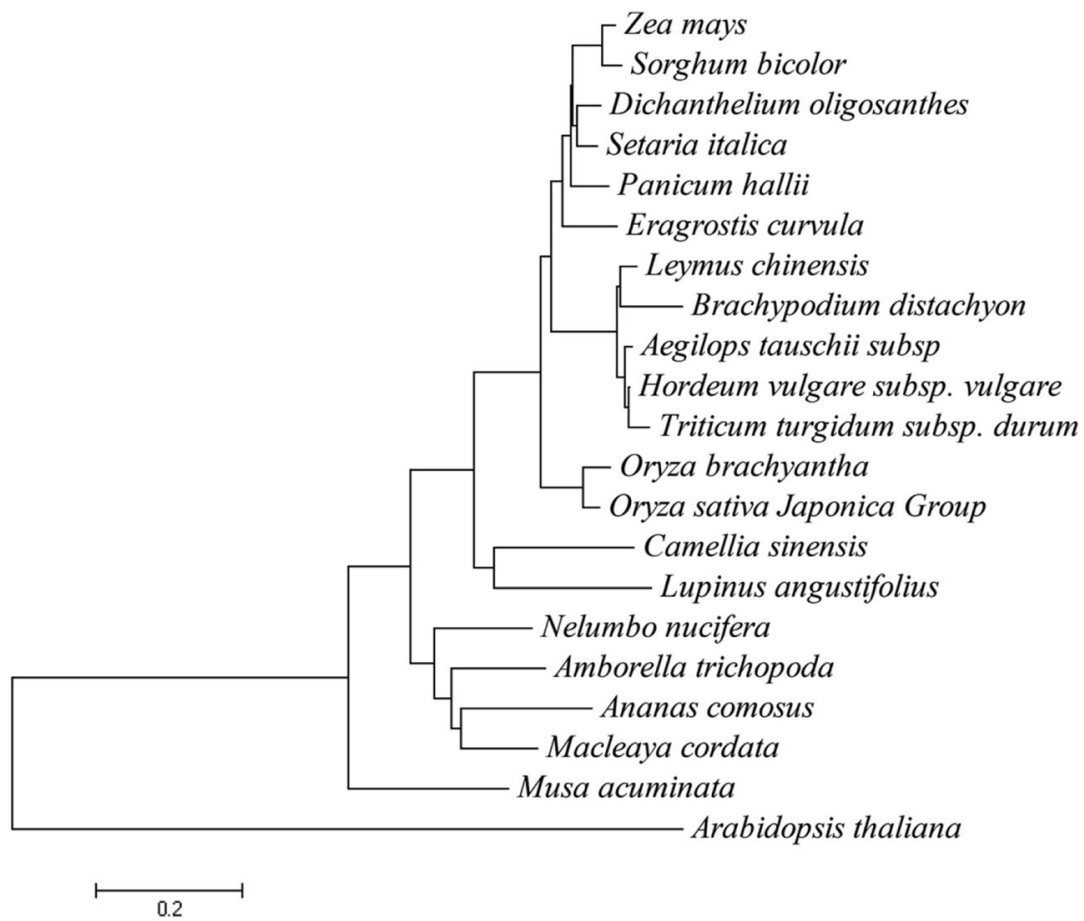

Fig. 1 Sequence analysis of LCMYB4 and its homologs. a Comparison of the amino acid sequences of thirteen MYB4 proteins, i.e., Arabidopsis thaliana, Aegilops tauschii, Brachypodium distachyon, Dichanthelium oligosanthes, Eragrostis curvula, Hordeum vulgare, Oryza brachyantha, Oryza sativa Japonica, Panicum hallii, Setaria italic, Sorghum bicolor, Triticum turgidum, Zea mays, etc. b Phylogenetic analysis of LCMYB4 and homologs was constructed based on peptide sequences using a neighbor-joining method

\section{Expression analysis of $L C M Y B 4$}

The expression of the LcMYB4 gene in leaves, stems, roots, stamens, and carpel was analyzed by quantitative RT-PCR, and the results showed that LcMYB4 was more highly expressed in carpel, stem, and leaf, but the relative expression in stamens was lower (Fig. 2a). Moreover, the expression pattern of LcMYB4 under abiotic stress was also studied. At 4 weeks, seedlings were subjected to low temperature at $4{ }^{\circ} \mathrm{C}, 100 \mu \mathrm{M}$ abscisic acid (ABA), $200 \mathrm{mM}$ $\mathrm{NaCl}$, or $300 \mathrm{mM}$ mannitol. RNA was extracted at different time points $(0 \mathrm{~h}, 1 \mathrm{~h}, 2 \mathrm{~h}, 4 \mathrm{~h}, 8 \mathrm{~h}, 12 \mathrm{~h}$ and $24 \mathrm{~h})$.
QRT-PCR analysis showed that the level of the LcMYB4 gene was significantly induced by cold treatment, with the highest expression at $8 \mathrm{~h}$. However, LcMYB4 gene expression was not induced by $\mathrm{NaCl}$ treatment and was inhibited by ABA and mannitol treatment (Fig. 2b).

\section{Subcellular localization and transactivation assay of LcMYB4}

To determine the subcellular localization of LcMYB4, the gene was loaded into the PCAMBIA1302 vector, and the fused protein, 35S::LcMYB4-GFP, was immediately 

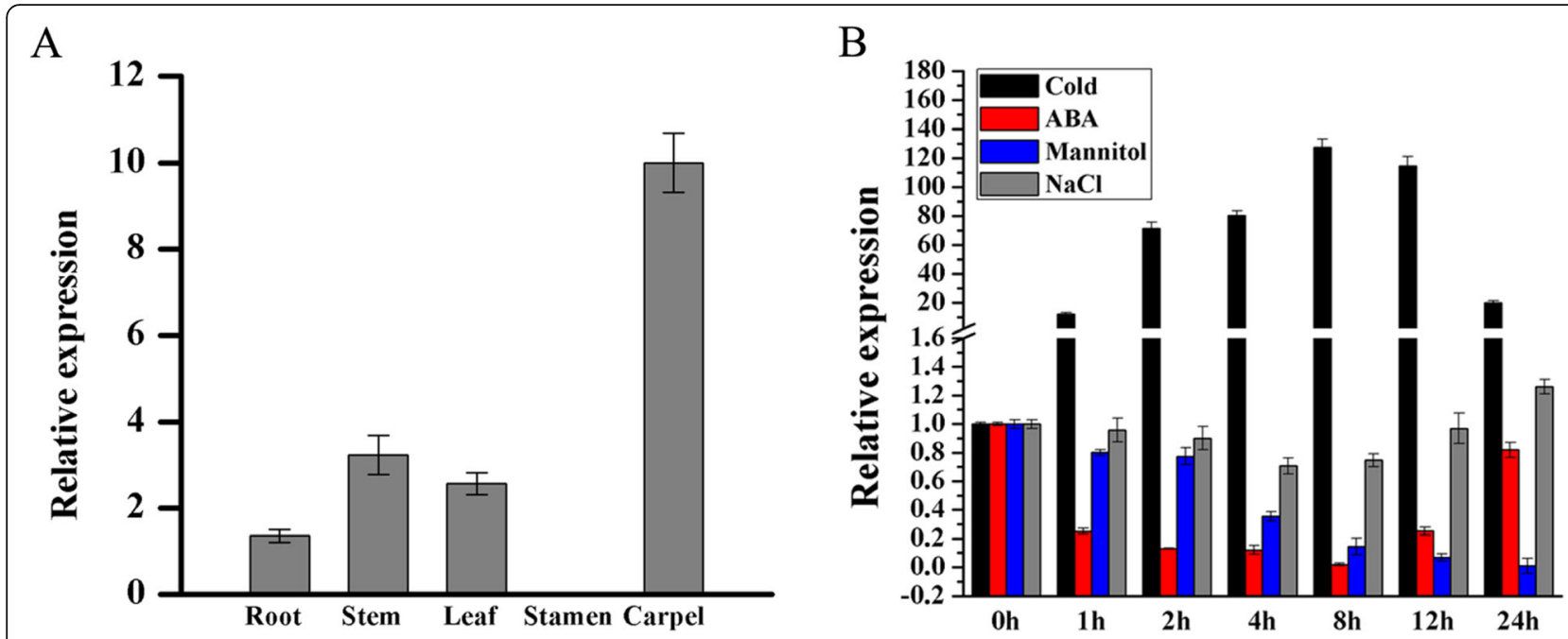

Fig. $\mathbf{2}$ The expression pattern analysis of LCMYB4. a Expression of LCMYB4 in various tissues as determined by quantitative RT-PCR. $\mathbf{b}$ Four-weekold seedlings were treatment with different stress and the expression of LCMYB4 under cold, ABA mannitol, and NaCl treatments for the indicated lengths of time as determined by quantitative RT-PCR. Data are presented as the mean of three replicates \pm SD

transformed into tobacco (Nicotiana benthamiana) leaf epidermal cells. The results showed that the fluorescence of 35S::GFP was distributed in the nucleus, cell membrane and cytoplasm, while that of 35S::LcMYB4-GFP was only located in the nucleus (Fig. 3a).

The ORF of LcMYB4 was inserted into the pBridge vector, and the recombinant vector pBridge-LcMYB4 (experimental group), empty vector pBridge (negative control) and pBridge-LcWRKY5 (positive control) were each transferred into yeast strain AH109. The yeast was screened and cultured on SD/-His-Trp-free double-deficiency medium, and then the activity of betagalactosidase was detected. As shown in Fig. 3b, the yeast strains with empty vectors could not grow on double-deficiency medium, while the yeast strains with pBridge-LcMYB4 and pBridge-LcWRKY5 could grow on SD/-His-Trp medium. Furthermore, the filter paper of the positive control (pBridge-LcWRKY5) and the experimental group (pBridge-LcMYB4) showed obvious blue, while the negative control (pBridge) did not show blue (Fig. 3b). These results suggested that the LcMYB4 protein had transcriptional activation activity.

\section{Overexpression of LCMYB4 enhances chilling resistance during seed germination}

Since $L C M Y B 4$ was significantly induced by cold treatment, we further tested whether LCMYB4 is involved in the adaptation to chilling stress during the seed germination stage using three overexpressing lines, L1, L2 and L4, and the transcription levels are shown in Additional file 2: Figure S1. The results indicated that there were no differences in the germination rates of overexpressing lines and WT plants under normal condition, while the germination rates of overexpressing lines were 64.3, 54.9, and 69.1\%, respectively, and WT was only $30.1 \%$ under $4{ }^{\circ} \mathrm{C}$ conditions (Fig. 4a, b). In addition, the effect of chilling stress on seedling development ware also investigated. Our results indicated that the growth of shoot or root were no significant difference between overexpressed plants and wild plants (Fig. 4c). However, the primary root elongation of overexpressing plants was significantly longer than the WT plants at $4{ }^{\circ} \mathrm{C}$ for $50 \mathrm{~d}$ (Fig. 4c, d). These results indicate that $L c M Y B 4$ overexpression enhances chilling resistance during seed germination and seedling development.

\section{Effects of $L C M Y B 4$ overexpression on freezing tolerance}

We next investigated whether $L C M Y B 4$ is involved in the adaptation to freezing stress in transgenic Arabidopsis. Three weeks of WT and LcMYB4-overexpressing plants were acclimated at $4{ }^{\circ} \mathrm{C}$ for $2 \mathrm{~d},-8^{\circ} \mathrm{C}$ freezing treatment for $8 \mathrm{~h}$, and then recovered for $10 \mathrm{~d}$. Our results showed that there were no striking phenotypic differences between LcMYB4-overexpressing lines and WT plants under normal growth conditions; however, the overexpressing lines displayed more freezing tolerance than WT plants after $-8^{\circ} \mathrm{C}$ freezing treatment (Fig. 5a). The survival rates of three overexpressing lines were 95, 92, and $96 \%$, while that of wild type was only $60 \%$ (Fig. 5 b). In addition, the pedicel length of the transgenic plants was significantly longer than that of the wild type (Fig. $5 \mathrm{c}$ ). These results indicated that the overexpression of LcMYB4 significantly improved the freezing resistance of Arabidopsis. 

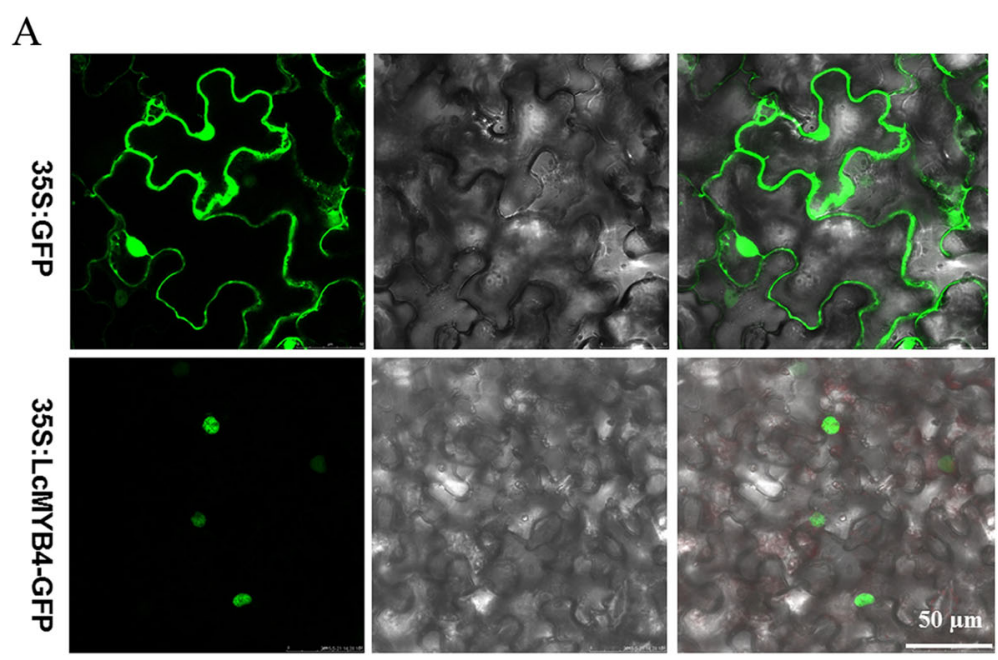

$\mathrm{B}$

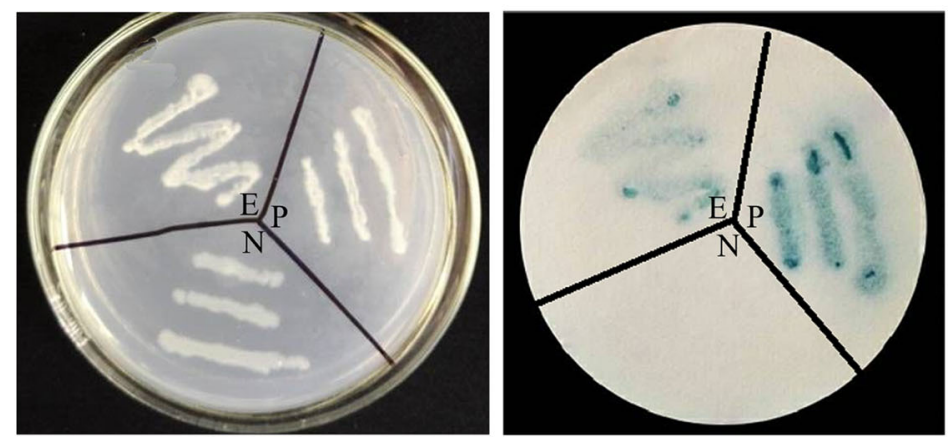

Fig. 3 Subcellular localization and transactivation assay of LCMYB4. a Subcellular localization of LCMYB4 in tobacco (Nicotiana benthamiana) leaf epidermal cells. 35S:GFP and 35S:LcMYB4 plasmids were transformed into tobacco leaf epidermal cells, and GFP fluorescence was visualized under a confocal laser-scanning microscope. From left to right, GFP fluorescence, bright-field, and overlays of the GFP fluorescence and bright-field. Bar = $50 \mu \mathrm{m}$. b Transactivation assay of LCMYB4. E, Experimental group (pBridge-LCMYB4) P, Positive control (pBridge-LCWRKY5); N, Negative control (pBridge)

\section{LCMYB4 overexpression enhanced chilling stress resistance during the reproductive stage}

To observe the effect of chilling on the reproduction stage of transgenic Arabidopsis, we selected L4 to further study which transcription levels were highest than other transgenic lines (Additional file 2: Figure S1). Then, we cut off the flowering florets of WT and L4 plants, leaving the florets to be pollinated during the florescence stage. WT and transgenic plants were treated in a low temperature incubator at $4{ }^{\circ} \mathrm{C}$ for $0 \mathrm{~h}, 48 \mathrm{~h}$ and $72 \mathrm{~h}$. Then, they were moved back to the normal condition at $22{ }^{\circ} \mathrm{C}$. After the end of seed filling, at least 30 long-horned fruits were sampled and calculated for each silique. Under normal growth conditions, the average number of seeds per mature silique was approximately 48 (Fig. 6 a, B). Under chilling stress for 48 h, the number of seeds in WT decreased significantly, with an average seed number of 23 per siliques, but only slightly in L4 seeds. Under chilling stress for $72 \mathrm{~h}$, the average number of seeds in WT and L4 siliques was 16 and 28, respectively (Fig. 6b). This indicated that the fertility of
LcMYB4 transgenic Arabidopsis was significantly higher than that of wild type plants under chilling treatment.

\section{LCMYB4 overexpression increased cold stress response- linked physiological indices}

Some physiological indices related to cold stress in Arabidopsis were determined. Chlorophyll is an important indicator of plant response to cold stress [36]. Our results showed that the total chlorophyll content of transgenic Arabidopsis was significantly higher than that of wild type plants (Fig. 3a), suggesting that chlorophyll degradation in transgenic plants may be less in transgenic plants under stress. Under normal conditions, the soluble sugar content of transgenic plants was significantly higher than that of wild type plants. Soluble sugar, as an important osmoprotectant in cell structure, can prevent plant cell dehydration and improve plant cold tolerance $[6,37]$. The increase in soluble sugar content indicates that transgenic plants have cold tolerance potential. Moreover, the soluble sugar content in transgenic lines is significantly higher than that in WT under cold conditions (Fig. 7b), which implies that 


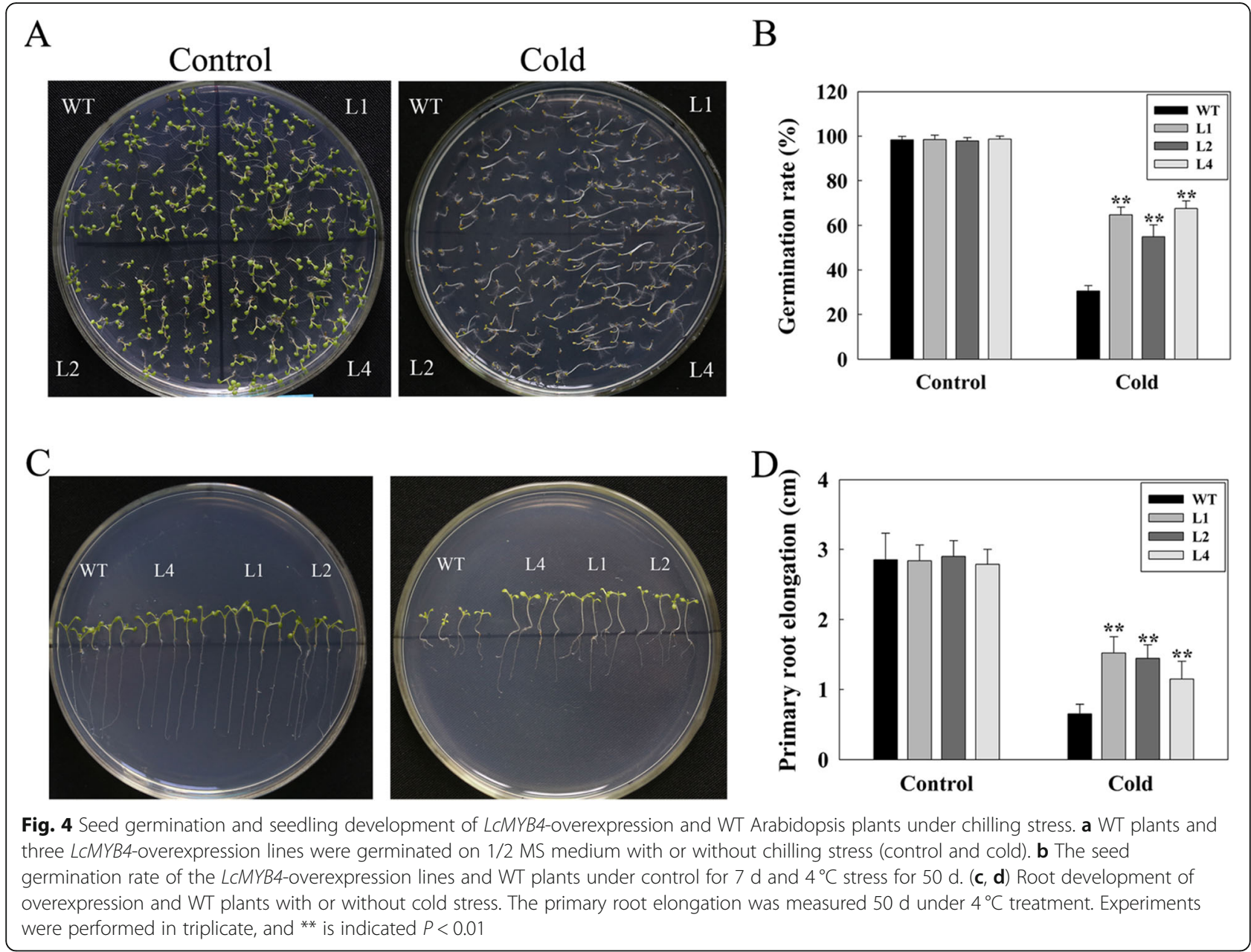

the tolerance to low cold stress can be improved by increasing the soluble sugar content by overexpressing the LCMYB4 gene $(P<0.01)$.

We also measured malondialdehyde (MDA), which is one of the products of peroxidized polyunsaturated fatty acids in plant membranes, and the higher content of MDA, the higher membrane damage caused by abiotic stress to plant cells [38]. Under cold conditions, the MDA content in one of the three LcMYB4-overexpression lines was less severe than that in wild-type plants, indicating a higher degree of lipid peroxidation in the transgenic plants (Fig. 7c). Superoxide dismutase (SOD), as a major antioxidant enzyme, can scavenge oxygen free radicals in plants and enhance their environmental adaptability [30, 39]. Furthermore, we analyzed the activities of SOD in LCMYB4-overexpressing lines and WT plants under low temperature $\left(4^{\circ} \mathrm{C}\right)$ and normal growth $\left(22^{\circ} \mathrm{C}\right)$ conditions. The results showed that the SOD activity in the L1, L2 and L4 transgenic lines was higher than that in WT plants under both normal and cold stress conditions $(P<0.01)$, suggesting that the antioxidant ability of transgenic plants was improved and that the ability to resist cold was enhanced (Fig. 7d). Altogether, these observations suggest that the overexpression of LcMYB4 in Arabidopsis improved the plant's tolerance to cold stresses.

\section{LCMYB4-overexpressing plants show altered expression of cold-responsive genes}

We further studied the relative expression levels of four cold stress-responsive genes to elucidate possible stress response mechanisms in the transgenic lines and WT plants, with and without cold stress. Our results suggested that the expression of the transcription factor genes $C B F 1$ and the cold-inducible genes KIN1, KIN2 and RCI2A were significantly increased in transgenic plants with cold treatment compared with the control plants (Fig. 8, Additional file 3: Figure S2). However, the expression levels of these genes were not significantly different between transgenic plants and WT plants without cold stress.

Identification and analysis of LCMYB4-interacting proteins To identify proteins that interact with LcMYB4, the cDNA was cloned into a pET30a expression vector. To obtain the purified recombinant protein, LcMYB4 was fused with 


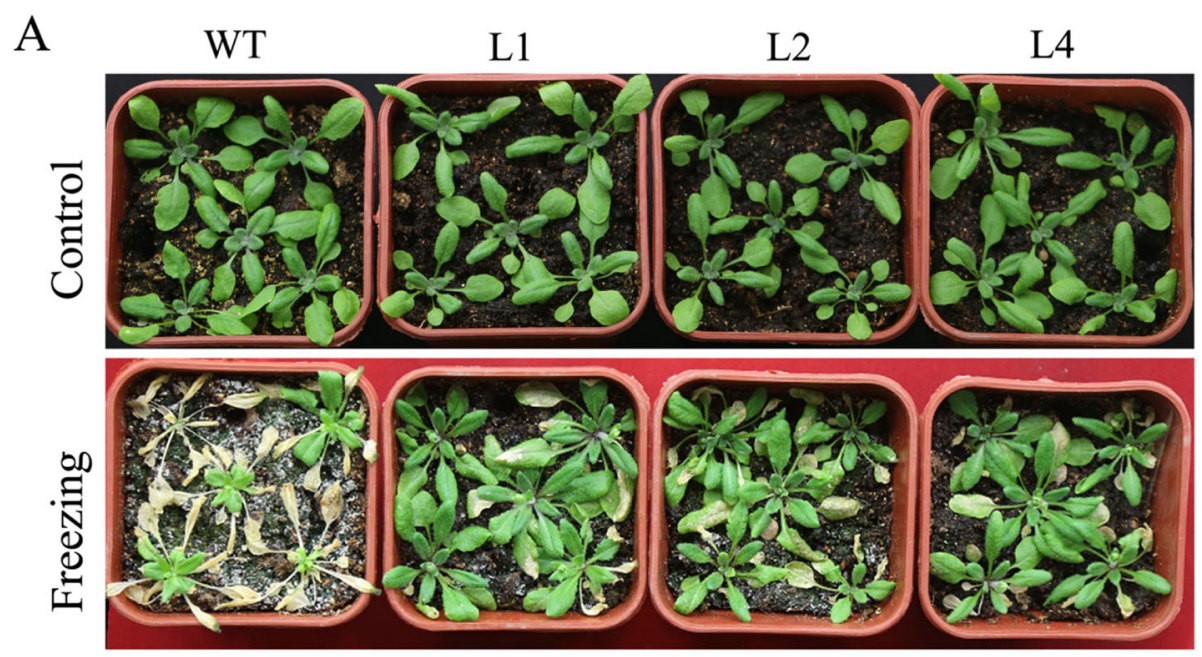

$\mathrm{B}$

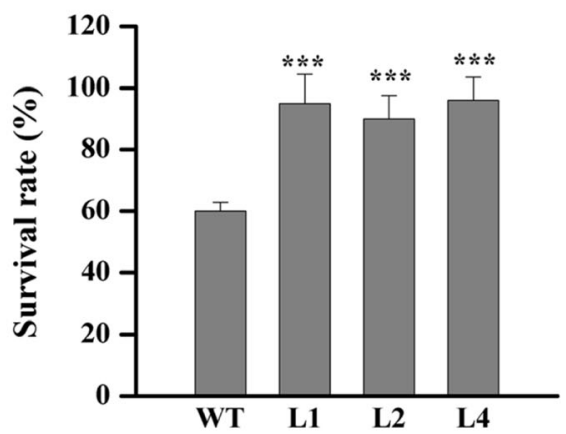

C

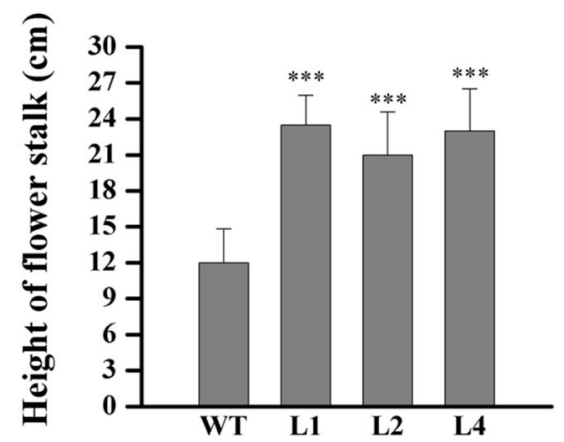

Fig. 5 Freezing tolerances of LCMYB4-overexpressing Arabidopsis. a Performance of WT and transgenic lines under normal conditions (control) and freezing treatment $\left(-8^{\circ} \mathrm{C}\right.$ for $8 \mathrm{~h}$, and recovered for $\left.10 \mathrm{~d}\right)$. (b, c) Survival rates and height of flower stalk of transgenic and WT Arabidopsis after freezing treatments. Three-old plants were grown at $4^{\circ} \mathrm{C}$ for $2 \mathrm{~d}$, transferred to $-8^{\circ} \mathrm{C}$ for $8 \mathrm{~h}$, and then grown under normal conditions to recovery for $10 \mathrm{~d}$. Experiments were performed in triplicate, and ${ }^{* * *}$ is indicated $P<0.001$
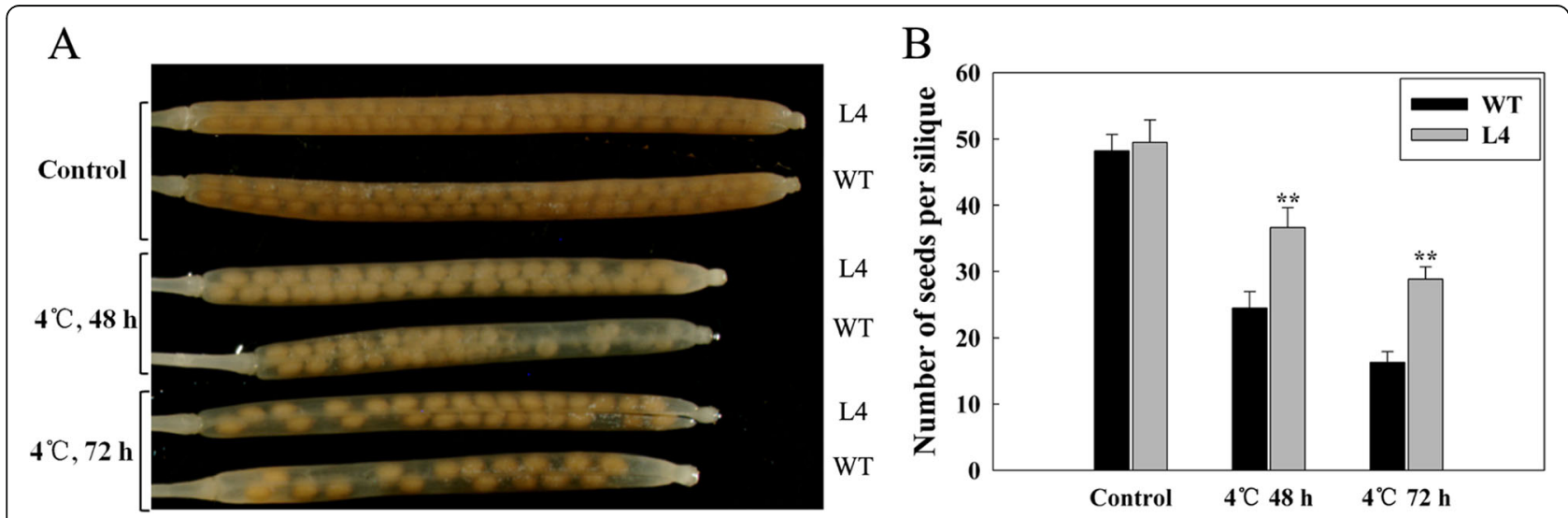

Fig. 6 Chilling tolerances of LCMYB4-overexpressing Arabidopsis during the reproductive stage. a Phenotype of seed set within mature siliques from chilling-stressed transgenic and wild-type Arabidopsis. $\mathbf{b}$ The number of seeds per silique of cold-stressed transgenic and wild-type Arabidopsis. Experiments were performed in triplicate, and ${ }^{* *}$ is indicated $P<0.01$ 


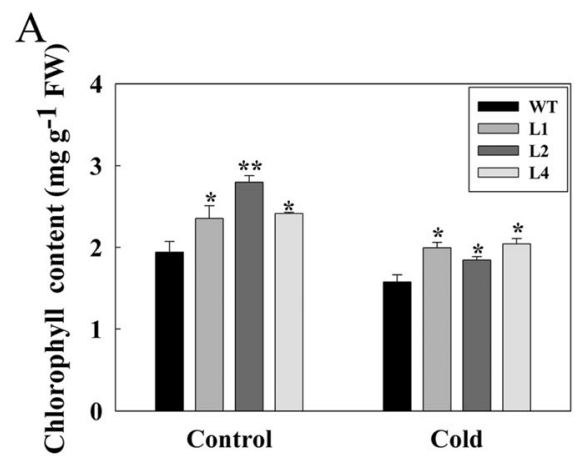

B
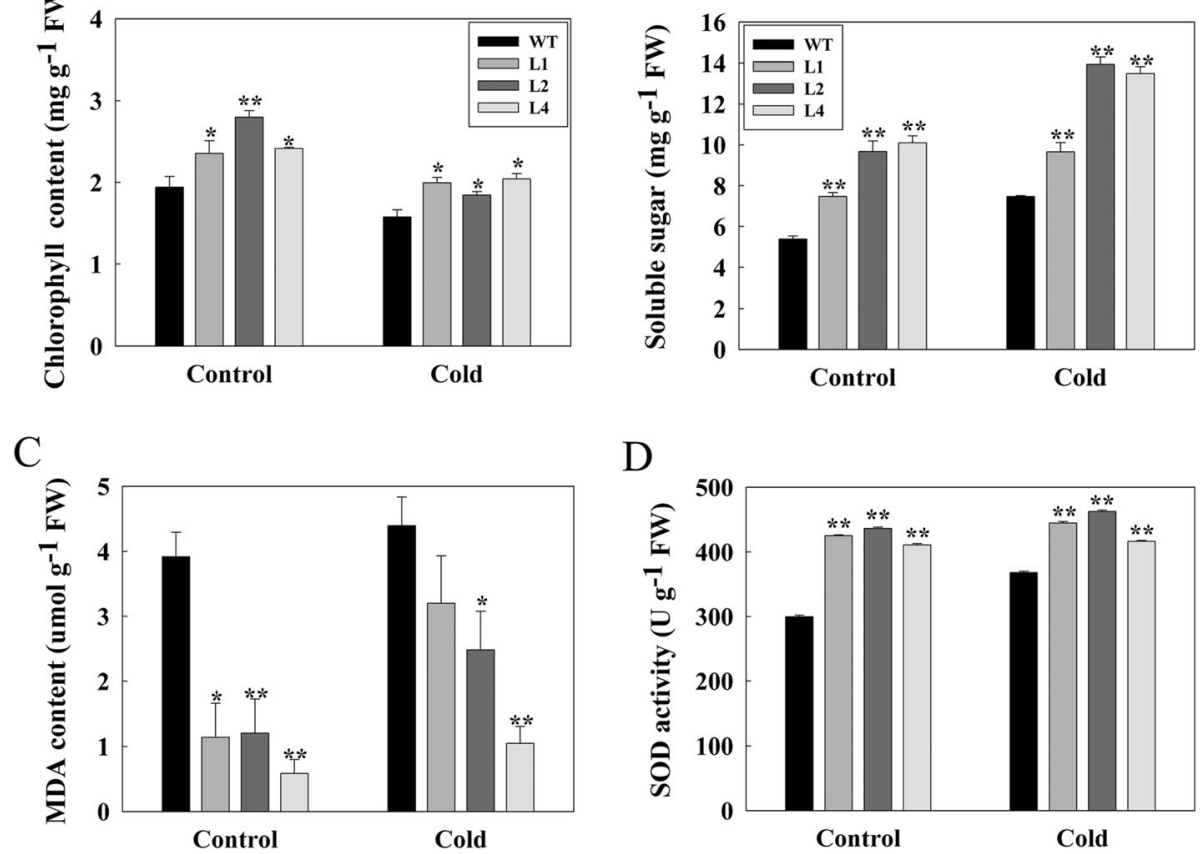

$\mathrm{D}$

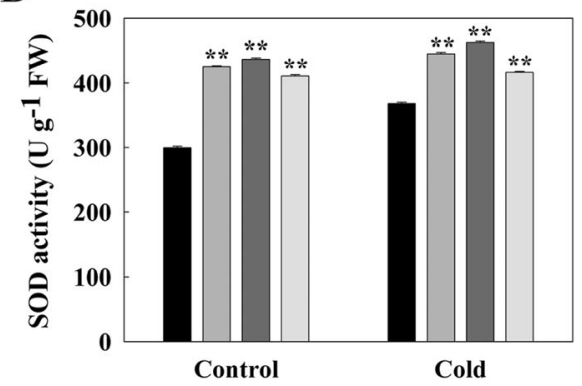

Fig. 7 Analysis of chlorophyll (a), soluble sugar (b), MDA (c), and SOD (d) contents in LcMYB4-overexpressing lines and WT plants. Three-week-old plants were transferred to $4^{\circ} \mathrm{C}$ for $2 \mathrm{~d}$, and the leaves were collected and measured. Experiments were performed in triplicate. ${ }^{*}$ and ${ }^{*}$ are indicated $P<0.05$ and $P<0.01$, respectively

a His tag, and the recombinant plasmid was induced to be expressed in E. coli BL21 (DE3) and purified by His column. An IPTG-induced band of the expected size of 40 $\mathrm{kDa}$ (with the theoretical value of LcMYB4 protein $31 \mathrm{kDa}$ plus the 6 His tag) and the purified LcMYB4-His recombinant protein is shown in Additional file 4: Figure S3.

Furthermore, the protein extracts of sheepgrass seedlings were added, and the nonspecific binding proteins were removed by using imidazole buffer $(10 \mathrm{mM}-100 \mathrm{mM})$ with

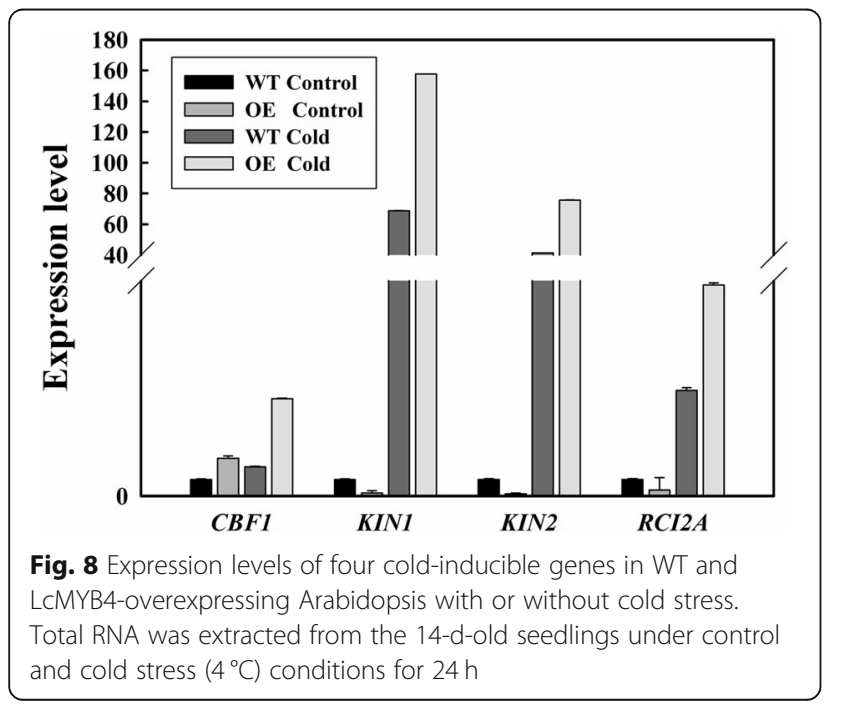

different concentration gradients. After the LcMYB4 binding protein was eluted with $250 \mathrm{mM}$ imidazole buffer, the differential bands were detected by SDS-PAGE electrophoresis and identified by mass spectrometry. The results of mass spectrometry identification are in Additional file 5: Table S2. Based on sequence alignment and homologous gene function prediction, we identified a candidate protein for LcMYB4 by mass spectrometry, which is a fructose-1,6bisphosphate aldolase (FBA1). The ORF region of the gene was cloned and named LcFBA1. The LcFBA1 protein has 98, 97, 94 and 88\% homology with fructose-1,6-diphosphate aldolase 1 in Triticum aestivum, Aegilops tauschii, Brachypodium distachyon, and Oryza sativa, respectively (Additional file 6: Figure S4).

LcFBA1 and LcMYB4 were then linked to $\mathrm{AD}$ and $\mathrm{BD}$ vectors of the yeast two-hybrid system, respectively. To avoid false positive phenomena caused by self-activation, we first transfected the LcMYB4 gene into a BD yeast expression vector to eliminate self-activation. The results showed that yeast with $\mathrm{BD}$ vector could not grow on SDTrp-His-Ade + Amp, $5 \mathrm{mM}$ 3-AT. The yeast transformed with $\mathrm{AD}$ and $\mathrm{BD}$ plasmids could grow normally on SDLeu-Trp-His-Ade + Amp + Kan, 5 mM 3-AT medium. The interaction between pGADT7 and the pGBKT7 empty vector served as a negative control. In the middle, the yeast medium containing two plasmids was diluted to different multiples and cultured on four-deficiency 
medium with $5 \mu \mathrm{L}$. After 1 week, yeast growth was observed. The right side corresponds to the detection of beta-galactosidase activity. The results showed that the LcMYB4 protein interacted with the LcFBA1 protein, as shown in Fig. 9a.

The expression of LcFBA1 and LcMYB4 was significantly induced by low temperature. The expression of LcFBA1 was upregulated by 13.94 times that of CK at 2 $\mathrm{h}$ of cold treatment and reached its peak at $8 \mathrm{~h}$ of cold treatment, which was 114 times that of CK (Fig. 9b). The expression of the LcMYB4 gene peaked at $8 \mathrm{~h}$ under low temperature stress (Fig. 9b).

\section{Discussion}

LCMYB4, a MYB transcription factor gene, induced by cold stress from sheepgrass

Sheepgrass is one of most important perennial forages in China and can survive severe environmental conditions.
Through transcriptome analysis, many $\mathrm{TF}$ genes were found to be significantly induced by abiotic stress in sheepgrass, such as LcDREB2a [40], LcWRKY5 [32], and LcMYB1 [35]. Meanwhile, the function of several cold-related genes has been reported in our previous studies $[28,30]$. Here, we first reported the mechanisms and functional roles of $L c M Y B 4$, from sheepgrass. Our results indicated that the genes contains the SANT/MYB superfamily domain and that the homology of LcMYB4 with $H$. vulgare, A. tauschii, and rice were 95, 94, 80\%, respectively (Fig. 1). However, the function of its homologous genes has also not been studied.

Moreover, the expression of LcMYB4 was rapidly induced by cold treatment; its expression peaked after exposure to $4{ }^{\circ} \mathrm{C}$ for $8 \mathrm{~h}$ and decreased thereafter (Fig. 2). However, the expression of LcMYB4 was not upregulated by salt and ABA stresses. Previous studies found

A

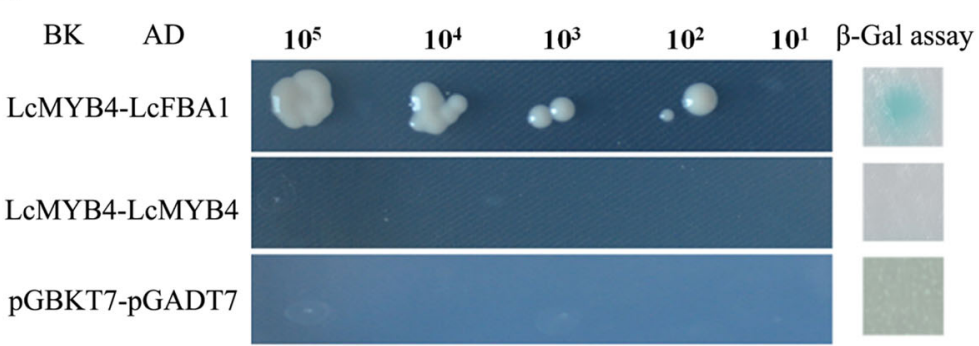

B

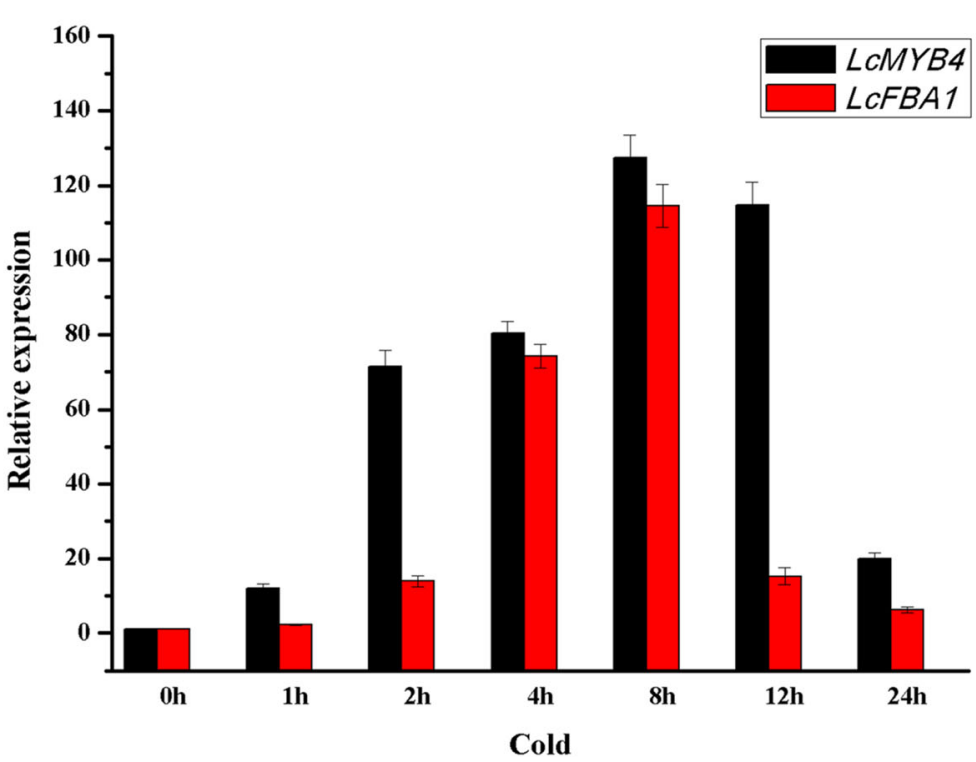

Fig. 9 Analysis of LCMYB4-interacting protein. a Yeast two-hybrid analysis of LCMYB4 and LCFBA1. Serial dilutions (10 $\left.{ }^{5}-10^{1}\right)$ of yeast cells containing different plasmid combinations were grown on the selective medium plates SD/-Trp-Leu-His-Ade/5 mM-AT. Colony growth indicated that the interaction represents stronger interactions. The interaction of pGADT7 and pGBKT7 served as a negative control. $\mathbf{b}$ Expression pattern analysis of LCMYB4 and LCFBA1 under cold stress by quantitative RT-PCR. Data are presented as the means of three replicates \pm SD 
that the many $M Y B$ genes from rice and a sheepgrass R1-MYB TF LcMYB1 are also induced by cold stress [5, $25,35,41,42]$. In addition, subcellular localization and transcriptional activation experiments showed that LcMYB4 was located in the nucleus and had transcriptional activation activity (Fig. 3). Therefore, LcMYB4 is MYB gene in sheepgrass that is induced exclusively by cold stress.

\section{LCMYB4 positively modulates chilling and freezing tolerance in Arabidopsis}

To investigate the role of $L c M Y B 4$ in tolerance to chilling and freezing stress, this study generated transgenic Arabidopsis with LcMYB4 overexpression because genetic transformation in sheepgrass is still very difficult [43]. LcMYB4 overexpression enhanced chilling resistance during seed germination and seedling development, mainly reflected on the germination rates, and primary root elongation was significantly higher in transgenic plants than in WT plants (Fig. 4). Furthermore, LcMYB4 overexpression enhanced freezing tolerance after $2 \mathrm{~d}$ of cold acclimation in transgenic Arabidopsis (Fig. 5).

In addition, the effect of chilling on the seed setting of Arabidopsis was studied, and the results indicated that the number of seeds per silique in the WT line was less than in the transgenic line under chilling stress for $48 \mathrm{~h}$ (Fig. 6). Several studies have found that the heterologous expression of the MYB gene can enhance the abiotic stress resistance of transgenic A. thaliana [44, 45]. For example, a wheat TaMYB30-B can improve drought stress tolerance in transgenic Arabidopsis [46]. The overexpression of the rice Osmyb4 and OsMYB3R-2 genes increases the freezing tolerance of transgenic $A$. thaliana plants [23, 41]. Moreover, recent research found that the Myb-like protein DRMY1 regulates cell expansion and seed production in Arabidopsis [19], while our research indicates that LcMYB4 overexpression increases the number of seeds per silique under chilling stress. Thus, our results clearly reveal that LCMYB4 is an important positive mediator in the response to chilling and freezing stress.

\section{Possible mechanisms responsible for the enhanced plant cold resistance in LCMYB4-overexpressing plants}

To elucidate the possible mechanisms for the increased cold tolerance in LcMYB4-overexpressing plants, several physiological indices were analyzed, such as chlorophyll, soluble sugar, MDA and SOD. Chlorophyll content has been widely used to evaluate the plant stress response [28], and our results indicated that the total chlorophyll content of transgenic plants was higher than that of WT plants (Fig. 7Ab). Previous studies showed that the soluble sugar contents increased significantly when the plant responded to different environmental stresses [5,
47, 48]. Our study found that expressing LcMYB4 increased the biosynthesis of soluble sugars in transgenic plants under normal and cold conditions (Fig. 7b), which may be partially responsible for the increased cold tolerance in LcMYB4-overexpressing plants.

Furthermore, this study indicated that MDA content and SOD activity were also significantly different between transgenic plants and wild-type plants. MDA is an indicator of plant cell membrane damage under stress [38], and SOD can scavenge oxygen free radicals in plants and enhance their environmental adaptability [30, 39]. The MDA content in one of the three LcMYB4overexpression lines was less severe than that in WT plants (Fig. 7c), while the activities of SOD in LcMYB4overexpression lines was higher than that of WT plants (Fig. 7d). In this study, we speculate that it may be due to the alleviation of oxidative damage and membrane damage, resulting in the enhanced cold resistance of LcMYB4-overexpressing plants.

\section{Overexpression of LCMYB4 increases the expression of cold-responsive genes in Arabidopsis}

To clarify the function of genes, we should further understand the abiotic stress signaling pathways in transgenic plants. CBF pathways are the most important pathways in the mediation of cold response and involve three TFs, $C B F 1, C B F 2$ and $C B F 3[9,49,50]$. Our results of four cold-response gene expression analyses suggest that the $C B F 1$ genes are strongly expressed under cold stress in transgenic plants compared with WT plants. Previous studies indicated that an inhibitor of calciumdependent protein kinases (CDPKs) and calmodulin inhibited the KIN genes expression and prevented cold acclimation [51]. KIN1 and KIN2 are two cold-induced genes in Arabidopsis that are coordinately regulated in response to cold stress [51]. Furthermore, RCI2A (rare cold inducible gene 2A) is also an important coldinducible gene in Arabidopsis [52]. We detected the expression levels of the cold-inducible KIN1, KIN2, and $R C I 2 A$ genes in transgenic and WT Arabidopsis. The expression levels of the KIN1 and KIN2 genes were significantly increased under cold conditions in transgenic plants (Fig. 8). Similar to the KIN genes, the overexpression of $L C M Y B 4$ significantly upregulated the expression level of the RCI2A gene. Overall, our results suggested that $L c M Y B 4$ is a TF gene and that overexpression of the $L c M Y B 4$ gene may involve cross-talk with the CBF1 TF gene and increase the expression of cold-inducible genes.

\section{LcMYB4 can interact with LcFBA1 protein}

Fructose-1,6-bisphosphate aldolases (FBA) are one of the most important enzymes in the Calvin-Benson cycle $(\mathrm{CBC})$, and $F B A$ genes are significantly induced in 
response to various stresses; moreover, the overexpression of FBA genes can enhance the resistance of transgenic plants to abiotic stresses, including $\mathrm{ABA}, \mathrm{NaCl}$, low temperature and drought [53-55].. Previous study has found that FBA can bind to MADS proteins, which is a MADS box transcription factor, revealing possible important molecular functions in plant physiological and biochemical metabolism [56]. In the present study, we first found that LcFBA1 is a protein that interacts with LcMYB4 in sheepgrass (Additional file 5: Table S2). Furthermore, our results showed that LcMYB4 could interact with LcFBA1 in vitro, as verified by yeast two-hybrid assays (Fig. 9a). In addition, the expression pattern analysis showed that both the LCMYB4 and LcFBA1 genes were both upregulated during cold induction (Fig. 9b). Thus, we speculated that LcMYB4 can interact with LcFBA1 to regulate the expression of downstream genes in response to cold stress in sheepgrass.

\section{Conclusions}

Our study identified an unknown function transcription factor gene, $L c M Y B 4$, from sheepgrass that plays important roles in the plant response to cold stress. The overexpression of LcMYB4 in Arabidopsis led to greater germination rate, survival rate, and seed setting rate through increases in soluble sugar content, leaf chlorophyll content and SOD activity, upregulation of the expression level of CBF1, KIN1, KIN2, and RCI2A genes, and decreased MDA content under cold stress conditions. Furthermore, our results indicated that LcMYB4 can interact with the LcFBA1 protein in sheepgrass and that the expression of the $L c F B A 1$ gene was induced by cold stress. Therefore, we speculated that $L c M Y B 4$ is a positive regulator that mediates cold tolerance and provides a promising genetic resource for improving the cold tolerance of other crops.

\section{Methods \\ Plant materials, growth conditions and experimental treatments}

Sheepgrass (variety Zhongke No. 1), Arabidopsis thaliana (Columbia-0 ecotype) and tobacco (Nicotiana benthamiana) were used in this study. Zhongke No. 1 is an improved variety by our laboratory, and certificated by the National Grass Seed Certification Committee in China in May 2014. Arabidopsis seeds acquired from the Arabidopsis Biological Resource Center (https://abrc.osu.edu/). $N$. benthamiana seeds were obtained from Dr. Yunhai Li of the Institute of Genetics and Developmental Biology, the Chinese Academy of Science. Arabidopsis and tobacco seeds were planted in pots and grown in a greenhouse under approximately $23^{\circ} \mathrm{C}$ and a $16 \mathrm{~h}$ day $/ 8 \mathrm{~h}$ night cycle.

The seeds of sheepgrass were grown in a mixture of peat moss and vermiculite $(2: 1, \mathrm{v} / \mathrm{v})$ at $28 / 16^{\circ} \mathrm{C}$ under 16-h light/8-h dark. Four-week-old seedlings were used for various stresses treatment. For cold stress, the seedlings were treated at $4{ }^{\circ} \mathrm{C}$ in a chamber. To test $\mathrm{ABA}$, drought and salt stresses tolerance, the seedlings were irrigated with $100 \mu \mathrm{M} \mathrm{ABA}, 300 \mathrm{mM}$ mannitol and 200 $\mathrm{mM} \mathrm{NaCl}$, respectively [33]. The seedlings were collected at different time intervals $(0,4,8$ and $12 \mathrm{~h})$ after abiotic stress treatments. Furthermore, the leaves, stems, roots, stamen and carpel were sampled at the time of flowering stage and stored at $-80^{\circ} \mathrm{C}$ for tissue-specific expression analysis.

\section{RNA isolation, gene clone and phylogenetic analysis}

Total RNA from sheepgrass seedlings and various tissues were isolated use a TRIzol kit (Invitrogen, Carlsbad, CA, USA) and treated with RNase-free DNase I (TaKaRa, Dalian, China) according to the manufacturer's instructions. Then, the first-strand cDNA synthesis was performed with a PrimeScript ${ }^{\circ}$ RT Reagent Kit (TaKaRa, Dalian, China).

Full-length sequence of LCMYB4 and LcFBA1 was amplified using the gene-specific primers supplied in Additional file 1: Table S1, and the amplification conditions were $95^{\circ} \mathrm{C}$ for $4 \mathrm{~min}$, followed by 32 cycles of $98^{\circ} \mathrm{C}$ for $10 \mathrm{~s}$, and $68^{\circ} \mathrm{C}$ for $90 \mathrm{~s}$. All the PCR products were purified, and an A tail was added. Then, the products were ligated into a pMD18-T vector (TaKaRa, Dalian, China) and sequenced.

The cloned gene sequences were searched and aligned using the National Center for Biotechnology Information (NCBI; https://www.ncbi.nlm.nih.gov/). DNAMAN was used for sequence alignment, and the neighbor-joining algorithm of MEGA6.0 was used for the phylogenetic tree analysis of MYB4 proteins [57]. SignalP4.1 was used for signal peptide prediction [58].

\section{Real-time RT-PCR analysis}

QRT-PCR was use to analysis the expression levels of $L C M Y B 4$ gene in various organs and under different abiotic stresses, and the expression levels of cold-inducible genes in LcMYB4-overexpressing and WT Arabidopsis. The cDNA template was amplified with a qRT-PCR system (Roche Light Cycler 480 II, Germany) using 40 cycles of $95^{\circ} \mathrm{C}$ for $5 \mathrm{~s}$ and $60^{\circ} \mathrm{C}$ for $20 \mathrm{~s}$, and the data were quantified using the $2^{-\Delta \Delta \mathrm{Ct}}$ methodas described by our previous studies [28, 31, 33]. All primers used in this study are listed in Additional file 1: Table S1. LCACTIN was used as the internal control.

\section{Subcellular localization and transactivation assay of LCMYB4}

The ORF sequence of $L c M Y B 4$ was inserted into the SpeI and BglII sites of vector pCAMBIA1302 to express fusion proteins with green fluorescence protein 
(GFP). The intact leaves of 4-week-old wild type (WT) tobacco (Nicotiana tabacum) plants were injected with Agrobacterium tumefaciens harboring the pCAMBIA1302 vector and the fused protein pCAMBIA1302-LcMYB4-GFP. Transgene-derived expression was monitored 2 to $3 \mathrm{~d}$ after infiltration by confocal microscopy on an Olympus FV1000MPE microscope (Olympus, Japan), and fluorophores (GFP) were excited using an argon laser at $488 \mathrm{~nm}$ [29].

To investigate the transcription activation activity, the ORFs were cloned into the pBridge vector by EcoRI and SalI sites and subsequently transformed into yeast strain AH109 as described by our previous studies [30, 31]. The PBridge vector was used as a negative control, and pBridge-LcWRKY5 was used as a positive control [32]. The yeast was screened and cultured on SD/-His-Trpfree double-deficiency medium, and the $\beta$-galactosidase (LacZ reporter) assay was performed on sterile filter paper according to a previous study [59].

\section{Plasmid construction and plant transformation}

To induce the constitutive expression of $L c M Y B 4$, the ORF sequences were inserted into the pSN1301 vector under the control of the cauliflower mosaic virus $35 \mathrm{~S}$ (CaMV 35S) promoter [60]. The recombinant plasmid pSN1301-LcMYB4 was introduced into Agrobacterium strain EHA105 using a freeze-thaw method [61] and further transformed into Arabidopsis using the floral dip method [62]. The seeds of transgenic plants were selected on $1 / 2$ MS medium supplied with hygromycin (50 $\mathrm{mg} \mathrm{L}^{-1}$ ) for 1 week and the seedlings were confirmed by PCR using the gene-specific primers, and then Arabidopsis seeds of T3 generations were obtained.

\section{Chilling and freezing stress tolerance assays in transgenic Arabidopsis}

The seeds of WT and three transgenic Arabidopsis lines (L1, L2 and L4) were germinated on MS medium and transferred to a $4{ }^{\circ} \mathrm{C}$ incubator. The control was placed in a $22^{\circ} \mathrm{C}$ greenhouse. After 4-5 weeks of low temperature incubation, the germination rate and cotyledon number were counted. A total of 150 seeds from each transgenic line and the WT line were used and each experiment was replicated three times. To determine the effect of chilling stress on root growth, seeds were germinated and grown on vertically standing plates. After $50 \mathrm{~d}$ of growth, the length of the primary root was measured.

To detect the chilling tolerances of LcMYB4-overexpressing Arabidopsis during the reproductive stage, transgenic and WT plants were grown in a small pot in a greenhouse. Flowers at developmental stage 13 were marked at a fixed time, the petals can be seen between the sepals and continue to elongate rapidly and the stigma is already receptive and anthesis occurs at this stage, $[63,64]$. For the cold treatment, the plants were placed in a $4{ }^{\circ} \mathrm{C}$ low temperature incubator for $0 \mathrm{~h}, 48 \mathrm{~h}$ or $72 \mathrm{~h}$ and then transferred back to $22^{\circ} \mathrm{C}$. After seed filling, more than 30 siliques were sampled, and the average number of seeds per silique was calculated.

For freezing stress tolerance experiments, three-weekold Arabidopsis plants grown under normal growth conditions were cold-acclimated at $4{ }^{\circ} \mathrm{C}$ for $2 \mathrm{~d}$ and transferred to a low-temperature chamber at $-8^{\circ} \mathrm{C}$ for $8 \mathrm{~h}$. The survival rates and height of the flower stalk of transgenic and WT Arabidopsis were detected after $10 \mathrm{~d}$ of recovery under normal conditions. Furthermore, forty seedlings from each transgenic line and the WT line were used for the freezing tolerance assay. Each experiment was replicated three times.

\section{Physiological index measurements}

To measure physiological indices, two-week-old seedlings were subjected to $4{ }^{\circ} \mathrm{C}$ for $2 \mathrm{~d}$. The chlorophyll content was measured as reported [29, 30]. In brief, the leaves were immersed in $95 \%$ ethanol at $22^{\circ} \mathrm{C}$ overnigh in darkness. Total superoxide dismutase (SOD) activity was monitored by nitro-blue tetrazolium (NBT) reduction method $[28,65]$. The soluble sugar and malondialdehyde (MDA) contents were measured based on the method described by previous studies [28, 34].

\section{Extraction of total protein from sheepgrass}

The extraction of whole protein from plants was mainly based on a previous study [66]. The leaves of 4-week-old sheepgrass seedlings were weighed at 0.5 $\mathrm{g}$, and $5 \mathrm{~mL}$ of extract buffer $\mathrm{E}(50 \mathrm{mM}$ Tris- $\mathrm{HCl}$ (pH 7.5), $50 \mathrm{mM}$ NaF, $1 \mathrm{mM}$ PMSF, $1 \mathrm{mM}$ DTT, 1 $\mathrm{mM} \mathrm{Na} \mathrm{VO}_{4}$, and $5 \mathrm{mM} \mathrm{MgCl}_{2}$ ) was added to a mortar to grind and form a homogenate. The homogenate was transferred to a $1.5 \mathrm{~mL}$ centrifuge tube for 14,000 $\mathrm{x} g$ for $40 \mathrm{~min}$, and the supernatant was passed through a Millex-GV filter with a porosity of $0.22 \mu \mathrm{m}$ to obtain the plant whole protein $[67,68]$.

\section{Pull-down analysis and screening of interactive proteins}

To obtain the protein interacting with LcMYB4, the ORF sequence of $L c M Y B 4$ was cloned into the pET-30a expression vector (Novagen, Madison, WI) to produce $\mathrm{His}_{6}$ tag-fused LcMYB4. The LcMYB4-His 6 fusion protein was coupled to amylose resin (New England Biolabs) according to the manufacturer's instructions, and then the protein extracts of sheepgrass seedlings were incubated with LcMYB4-His ${ }_{6}$-amylose resin at $4{ }^{\circ} \mathrm{C}$ for $4 \mathrm{~h}$. Subsequently, the nonspecific binding proteins were washed five times with imidazole buffer (10 $\mathrm{mM}-100 \mathrm{mM}$ ) with different concentration gradients. The bound proteins were eluted with SDS/PAGE 
sample buffer and resolved by SDS/PAGE followed by mass spectrometry $[69,70]$.

\section{Yeast 2-hybrid analysis}

For analysis the interaction of LcMYB4 and LcFBA1, the ORFs of the two genes were constructed into pGADT7 and pGBKT7 vectors (Clontech, Mountain View, CA, USA) and the constructs were cotransformed into Saccharomyces cerevisiae strain AH109. The transformants of LcMYB4 and LcFBA1 proteins were plated on SD/ -Trp-Leu-His-Ade medium containting $3 \mathrm{mM} 3$-amino1,2,4-triazole (3-AT) and incubated at $30^{\circ} \mathrm{C}$ for $4-6 \mathrm{~d}$ as our previously described [33]. Meanwhile, the single transformant with pGBKT7 was used for the autoactivation analysis as our previously reported [33].

\section{Statistical analysis}

SPSS 21.0 software (IBM, Chicago) was used for statistical analysis, and Student's t-test was used to compare different samples. The bars showed the mean and standard deviation (SD) of three independent experiments, and the sterisks represent significant differences. The differences between WT and LcMYB4-overexpressing plants were considered statistically significant if $p$-values were $<0.001,<0.01$ or $<0.05$.

\section{Supplementary information}

Supplementary information accompanies this paper at https://doi.org/10. 1186/s12870-020-02427-y.

Additional file 1: Table S1. All primers used in this study.

Additional file 2: Figure S1. (A) The positive transgenic lines determined by PCR. (B) The transcription levels of LCMYB4 gene in overexpressing lines.

Additional file 3: Figure S2. The expression levels of CBF1 gene in transgenic and WT plant during different time periods.

Additional file 4: Figure S3. (A) SDS-PAGE results of prokaryotic expression. M: Marker; 1: Before induction; 2-7: $0.5 \mathrm{mM}$ IPTG induced for $1 \mathrm{~h}, 2$ h, $3 \mathrm{~h}, 4 \mathrm{~h}, 5 \mathrm{~h}, 6 \mathrm{~h}$. (B) The purification of recombinant protein pET30aLCMYB4. M: Marker; 1: Before induction; 2: After induction; 3-7: The purified target protein.

Additional file 5: Table S2. LCMYB4 binding proteins in sheegrass seedling

Additional file 6: Figure S4. Phylogentic tree analysis of LCFBA1 and its homologous proteins.

\section{Abbreviations}

ABA: Abscisic acid; BLAST: Basic local alignment search tool; CaMV: Cauliflower mosaic virus; CDS: Coding sequences;

CDNA: Complementary DNA; GFP: Green fluorescent protein; GUS: ßGlucuronidase; MDA: Malondialdehyde; $\mathrm{NaCl}$ : Sodium chloride; NCBI: The national center for biotechnology information; ORF: Open reading frame; qRT-PCR: Quantitative real-time polymerase chain reaction; SOD: Superoxide dismutase; WT: Wild type

\section{Authors' contributions}

GL, LC and XL conceived and designed the experiments. JJ, LC, PZ, and XG performed most of the experiments. $\mathrm{XL}$ made substantial contributions to the data analysis and the manuscript writing. SC revised and edited the manuscript. GL gave the final approval the manuscript. DQ were involved in performing the experiments; All authors read and approved the final manuscript.

\section{Funding}

This work was supported by the Science and Technology Major Project of Inner Mongolia Autonomous Region of China, the National Natural Science Foundation of China (No.31601996), the National Key Research and Development Program of China (Grant No. 2018YFD1001000,

2016YFC0500700), Science and technology cooperation project between Jilin Province and Chinese Academy of Sciences (2019SYHZ0035) and Kulun Banner Science and Technology Poverty Alleviation Project of Chinese Academy of Sciences. The funders had no role in the design of the study and collection, analysis, and interpretation of data and in writing the manuscript, but just provide the financial support.

\section{Availability of data and materials}

The gene sequence is available in the NCBI gene database under the accession number MN327641 (https://www.ncbi.nIm.nih.gov/nuccore/MN327641). All data generated or analyzed during this study are included in this published article and its supplementary information files (Additional files 1, 2, 3, 4, 5 and 6).

Ethics approval and consent to participate

Not applicable.

\section{Consent for publication}

Not applicable.

\section{Competing interests}

The authors declare that they have no competing interests.

\section{Author details}

${ }^{1}$ Key Laboratory of Plant Resources, Institute of Botany, The Chinese Academy of Sciences, Beijing, China. ${ }^{2}$ Guangdong Provincial Key Laboratory for Crop Germplasm Resources Preservation and Utilization, Agro-biological Gene Research Center, Guangdong Academy of Agricultural Sciences, Guangzhou, China. ${ }^{3}$ College of management science and engineering, Hebei University of Economics and Business, Shijiazhuang, China.

Received: 6 September 2019 Accepted: 30 April 2020

Published online: 27 May 2020

References

1. Zinn KE, Tunc-Ozdemir M, Harper JF. Temperature stress and plant sexual reproduction: uncovering the weakest links. J Exp Bot. 2010;61(7):1959-68.

2. Thomashow MF. Plant cold acclimation: freezing tolerance genes and regulatory mechanisms. Annu Rev Plant Physiol Plant Mol Biol. 1999;50:57199.

3. Barrero-Gil J, Huertas R, Rambla JL, Granell A, Salinas J. Tomato plants increase their tolerance to low temperature in a chilling acclimation process entailing comprehensive transcriptional and metabolic adjustments. Plant Cell Environ. 2016;39(10):2303-18

4. Bolt S, Zuther E, Zintl S, Hincha DK, Schmulling T. ERF105 is a transcription factor gene of Arabidopsis thaliana required for freezing tolerance and cold acclimation. Plant Cell Environ. 2017:40(1):108-20.

5. Yang A, Dai X, Zhang WH. A R2R3-type MYB gene, OsMYB2, is involved in salt, cold, and dehydration tolerance in rice. J Exp Bot. 2012;63(7):2541-56.

6. Wang L, Cao HL, Qian WJ, Yao L, Hao XY, Li NN, et al. Identification of a novel bZIP transcription factor in Camellia sinensis as a negative regulator of freezing tolerance in transgenic arabidopsis. Ann Bot. 2017;119(7):1195209.

7. Kim SH, Kim HS, Bahk S, An J, Yoo Y, Kim JY, et al. Phosphorylation of the transcriptional repressor MYB15 by mitogen-activated protein kinase 6 is required for freezing tolerance in Arabidopsis. Nucleic Acids Res. 2017 45(11):6613-27. 
8. Ji H, Wang Y, Cloix C, Li K, Jenkins Gl, Wang S, et al. The Arabidopsis RCC1 family protein TCF1 regulates freezing tolerance and cold acclimation through modulating lignin biosynthesis. PLoS Genet. 2015;11(9):e1005471.

9. Chinnusamy V, Zhu J, Zhu JK. Cold stress regulation of gene expression in plants. Trends Plant Sci. 2007;12(10):444-51.

10. Shi Y, Ding Y, Yang S. Cold signal transduction and its interplay with phytohormones during cold acclimation. Plant Cell Physiol. 2015;56(1):7-15.

11. Liu Q, Kasuga M, Sakuma Y, Abe H, Miura S, Yamaguchi-Shinozaki K, et al. Two transcription factors, DREB1 and DREB2, with an EREBP/AP2 DNA binding domain separate two cellular signal transduction pathways in drought- and low-temperature-responsive gene expression, respectively, in Arabidopsis. Plant Cell. 1998;10(8):1391-406.

12. Chinnusamy V, Ohta M, Kanrar S, Lee BH, Hong X, Agarwal M, et al. ICE1: a regulator of cold-induced transcriptome and freezing tolerance in Arabidopsis. Genes Dev. 2003;17(8):1043-54.

13. Agarwal $M$, Hao $Y$, Kapoor A, Dong CH, Fujii H, Zheng $X$, et al. A R2R3 type MYB transcription factor is involved in the cold regulation of $C B F$ genes and in acquired freezing tolerance. J Biol Chem. 2006;281(49):37636-45.

14. Novillo F, Alonso JM, Ecker JR, Salinas J. CBF2/DREB1C is a negative regulator of CBF1/DREB1B and CBF3/DREB1A expression and plays a central role in stress tolerance in Arabidopsis. Proc Natl Acad Sci U S A. 2004; 101(11):3985-90

15. Oppenheimer DG, Herman PL, Sivakumaran S, Esch J, Marks MD. A Myb gene required for leaf Trichome differentiation in Arabidopsis is expressed in stipules. Cell. 1991;67(3):483-93.

16. Paz-Ares J, Ghosal D, Wienand U, Peterson PA, Saedler $\mathrm{H}$. The regulatory $\mathrm{C} 1$ locus of Zea mays encodes a protein with homology to myb protooncogene products and with structural similarities to transcriptional activators. EMBO J. 1987:6(12):3553-8.

17. Dubos C, Stracke R, Grotewold E, Weisshaar B, Martin C, Lepiniec L. MYB transcription factors in Arabidopsis. Trends Plant Sci. 2010;15(10):573-81.

18. Zhang Z, Liu X, Wang X, Zhou M, Zhou X, Ye X, et al. An R2R3 MYB transcription factor in wheat, TaPIMP1, mediates host resistance to Bipolaris sorokiniana and drought stresses through regulation of defense- and stressrelated genes. New Phytol. 2012;196(4):1155-70.

19. Wu P, Peng M, Li Z, Yuan N, Hu Q, Foster CE, et al. DRMY1, a Myb-like protein regulates cell expansion and seed production in Arabidopsis thaliana. Plant Cell Physiol. 2018;60(2):285-302.

20. Chen T, Li W, Hu X, Guo J, Liu A, Zhang B. A cotton MYB transcription factor, GbMYB5, is positively involved in plant adaptive response to drought stress. Plant Cell Physiol. 2015;56(5):917-29.

21. Wei H, Zhao H, Su T, Bausewein A, Greiner S, Harms K, et al. Chicory R2R3MYB transcription factors CiMYB5 and CiMYB3 regulate fructan 1exohydrolase expression in response to abiotic stress and hormonal cues. J Exp Bot. 2017;68(15):4323-38.

22. Wei H, Bausewein A, Greiner S, Dauchot N, Harms K, Rausch T. CiMYB17, a stress-induced chicory R2R3-MYB transcription factor, activates promoters of genes involved in fructan synthesis and degradation. New Phytol. 2017; 215(1):281-98

23. Dai $X, X u Y, M a Q, X u$ W, Wang $T$, Xue $Y$, et al. Overexpression of an R1R2R3 MYB gene, OsMYB3R-2, increases tolerance to freezing, drought, and salt stress in transgenic Arabidopsis. Plant Physiol. 2007;143(4):1739-51.

24. Mengiste T, Chen X, Salmeron J, Dietrich R. The BOTRYTIS SUSCEPTIBLE1 gene encodes an R2R3MYB transcription factor protein that is required for biotic and abiotic stress responses in Arabidopsis. Plant Cell. 2003:15(11): 2551-65.

25. Su CF, Wang YC, Hsieh TH, Lu CA, Tseng TH, Yu SM. A novel MYBS3dependent pathway confers cold tolerance in rice. Plant Physiol. 2010 153(1):145-58.

26. Bai Y, Han X, Wu J, Chen Z, Li L. Ecosystem stability and compensatory effects in the Inner Mongolia grassland. Nature. 2004:431(7005):181-4.

27. Chen $S$, Huang $X$, Yan X, Liang Y, Wang Y, Li X, et al. Transcriptome analysis in sheepgrass (Leymus chinensis): a dominant perennial grass of the Eurasian steppe. PLoS One. 2013;8(7):e67974.

28. Li X, Yang W, Liu S, Li XQ, Jia J, Zhao P, et al. LcFIN2, a novel chloroplast protein gene from sheepgrass, enhances tolerance to low temperature in Arabidopsis and rice. Physiol Plant. 2019;166:628-45.

29. Li X, Hou S, Gao Q, Zhao P, Chen S, Qi D, et al. LCSAIN1, a novel saltinduced gene from sheepgrass, confers salt stress tolerance in transgenic Arabidopsis and rice. Plant Cell Physiol. 2013;54(7):1172-85.
30. Gao Q, Li X, Jia J, Zhao P, Liu P, Liu Z, et al. Overexpression of a novel coldresponsive transcript factor LcFIN1 from sheepgrass enhances tolerance to low temperature stress in transgenic plants. Plant Biotechnol J. 2016;14(3): $861-74$.

31. Zhao P, Li X, Jia J, Yuan G, Chen S, Qi D, et al. LcbHLH92 from sheepgrass acts as a negative regulator of anthocyanin/proanthocyandin accumulation and influences seed dormancy. J Exp Bot. 2019;70:269-84.

32. Ma T, Li M, Zhao A, Xu X, Liu G, Cheng L. LCWRKY5: an unknown function gene from sheepgrass improves drought tolerance in transgenic Arabidopsis. Plant Cell Rep. 2014;33(9):1507-18.

33. Jia J, Zhao P, Cheng L, Yuan G, Yang W, Liu S, et al. MADS-box family genes in sheepgrass and their involvement in abiotic stress responses. BMC Plant Biol. 2018;18(1):42.

34. Li X, Gao Q, Liang Y, Ma T, Cheng L, Qi D, et al. A novel salt-induced gene from sheepgrass, LCSAIN2, enhances salt tolerance in transgenic Arabidopsis. Plant Physiol Biochem. 2013;64:52-9.

35. Cheng L, Li X, Huang X, Ma T, Liang Y, Ma X, et al. Overexpression of sheepgrass R1-MYB transcription factor LCMYB1 confers salt tolerance in transgenic Arabidopsis. Plant Physiol Biochem. 2013;70:252-60.

36. Kim JC, Lee SH, Cheong YH, Yoo CM, Lee SI, Chun HJ, et al. A novel coldinducible zinc finger protein from soybean, SCOF-1, enhances cold tolerance in transgenic plants. Plant J. 2001;25(3):247-59.

37. Ingram J, Bartels D. The molecular basis of dehydration tolerance in plants. Annu Rev Plant Physiol Plant Mol Biol. 1996;47:377-403.

38. RoyChoudhury A, Roy C, Sengupta DN. Transgenic tobacco plants overexpressing the heterologous lea gene Rab16A from rice during high salt and water deficit display enhanced tolerance to salinity stress. Plant Cell Rep. 2007;26(10):1839-59.

39. Erdal S, Genisel M, Turk H, Dumlupinar R, Demir Y. Modulation of alternative oxidase to enhance tolerance against cold stress of chickpea by chemical treatments (vol 175, pg 95, 2015). J Plant Physiol. 2015;189:113.

40. Peng XJ, Ma XY, Fan WH, Su M, Cheng LQ, Alam I, et al. Improved drought and salt tolerance of Arabidopsis thaliana by transgenic expression of a novel DREB gene from Leymus chinensis. Plant Cell Rep. 2011;30(8):1493502.

41. Vannini C, Locatelli F, Bracale M, Magnani E, Marsoni M, Osnato M, et al. Overexpression of the rice Osmyb4 gene increases chilling and freezing tolerance of Arabidopsis thaliana plants. Plant J. 2004;37(1):115-27.

42. Ma QB, Dai XY, Xu YY, Guo J, Liu YJ, Chen N, et al. Enhanced tolerance to chilling stress in OsMYB3R-2 transgenic Rice is mediated by alteration in cell cycle and ectopic expression of stress genes. Plant Physiol. 2009;150(1):24456.

43. Wang $L, L i X$, Chen S, Liu G. Enhanced drought tolerance in transgenic Leymus chinensis plants with constitutively expressed wheat TaLEA3. Biotechnol Lett. 2009:31(2):313-9.

44. He Y, Li W, LV J, Jia Y, Wang M, Xia G. Ectopic expression of a wheat MYB transcription factor gene, TaMYB73, improves salinity stress tolerance in Arabidopsis thaliana. J Exp Bot. 2012;63(3):1511-22.

45. Yao L, Jiang Y, Lu X, Wang B, Zhou P, Wu T. A R2R3-MYB transcription factor from Lablab purpureus induced by drought increases tolerance to abiotic stress in Arabidopsis. Mol Biol Rep. 2016;43(10):1089-100.

46. Zhang L, Zhao G, Xia C, Jia J, Liu X, Kong X. A wheat R2R3-MYB gene, TaMYB30-B, improves drought stress tolerance in transgenic Arabidopsis. J Exp Bot. 2012;63(16):5873-85

47. Gupta AK, Kaur N. Sugar signalling and gene expression in relation to carbohydrate metabolism under abiotic stresses in plants. J Biosci. 2005; 30(5):761-76.

48. Niu CF, Wei W, Zhou QY, Tian AG, Hao YJ, Zhang WK, et al. Wheat WRKY genes TaWRKY2 and TaWRKY19 regulate abiotic stress tolerance in transgenic Arabidopsis plants. Plant Cell Environ. 2012;35(6):1156-70.

49. Lee CM, Thomashow MF. Photoperiodic regulation of the C-repeat binding factor (CBF) cold acclimation pathway and freezing tolerance in Arabidopsis thaliana. Proc Natl Acad Sci U S A. 2012;109(37):15054-9.

50. Park S, Gilmour SJ, Grumet R, Thomashow MF. CBF-dependent and CBFindependent regulatory pathways contribute to the differences in freezing tolerance and cold-regulated gene expression of two Arabidopsis ecotypes locally adapted to sites in Sweden and Italy. PLoS One. 2018;13(12): e0207723.

51. Tahtiharju S, Sangwan V, Monroy AF, Dhindsa RS, Borg M. The induction of kin genes in cold-acclimating Arabidopsis thaliana. Evidence of a role for calcium. Planta. 1997;203(4):442-7. 
52. Medina J, Ballesteros ML, Salinas J. Phylogenetic and functional analysis of Arabidopsis RCl2 genes. J Exp Bot. 2007;58(15-16):4333-46.

53. Cai B, Li Q, Liu F, Bi H, Ai X. Decreasing fructose-1,6-bisphosphate aldolase activity reduces plant growth and tolerance to chilling stress in tomato seedlings. Physiol Plant. 2018;163(2):247-58.

54. Lu W, Tang X, Huo Y, Xu R, Qi S, Huang J, et al. Identification and characterization of fructose 1,6-bisphosphate aldolase genes in Arabidopsis reveal a gene family with diverse responses to abiotic stresses. Gene. 2012; 503(1):65-74.

55. Fan W, Zhang Z, Zhang Y. Cloning and molecular characterization of fructose-1,6-bisphosphate aldolase gene regulated by high-salinity and drought in Sesuvium portulacastrum. Plant Cell Rep. 2009;28(6):975-84.

56. Paez-Valencia J, Valencia-Mayoral P, Sanchez-Gomez C, Contreras-Ramos A Hernandez-Lucas I, Martinez-Barajas E, et al. Identification of Fructose-1,6bisphosphate aldolase cytosolic class I as an NMH7 MADS domain associated protein. Biochem Biophys Res Commun. 2008;376(4):700-5.

57. Tamura K, Stecher G, Peterson D, Filipski A, Kumar S. MEGA6: molecular evolutionary genetics analysis version 6.0. Mol Biol Evol. 2013;30(12):2725-9.

58. Petersen TN, Brunak S, von Heijne G, Nielsen H. SignalP 4.0: discriminating signal peptides from transmembrane regions. Nat Methods. 2011;8(10):7856.

59. Laporte SA, Oakley RH, Zhang J, Holt JA, Ferguson SS, Caron MG, et al. The beta2-adrenergic receptor/betaarrestin complex recruits the clathrin adaptor AP-2 during endocytosis. Proc Natl Acad Sci U S A. 1999;96(7):3712-7.

60. Ge L, Chen $H$, Jiang JF, Zhao Y, Xu ML, Xu YY, et al. Overexpression of OsRAA1 causes pleiotropic phenotypes in transgenic rice plants, including altered leaf, flower, and root development and root response to gravity. Plant Physiol. 2004;135(3):1502-13.

61. Jyothishwaran G, Kotresha D, Selvaraj T, Srideshikan SM, Rajvanshi PK, Jayabaskaran C. A modified freeze-thaw method for efficient transformation of agrobacterium tumefaciens. Curr Sci. 2007;93(6):770-2.

62. Clough SJ, Bent AF. Floral dip: a simplified method for agrobacteriummediated transformation of Arabidopsis thaliana. Plant J. 1998;16(6):735-43.

63. Smyth DR, Bowman JL, Meyerowitz EM. Early flower development in Arabidopsis. Plant Cell. 1990;2(8):755-67.

64. Zou CS, Jiang WB, Yu DQ. Male gametophyte-specific WRKY34 transcription factor mediates cold sensitivity of mature pollen in Arabidopsis. J Exp Bot. 2010;61(14):3901-14.

65. Durak I, Yurtarslanl Z, Canbolat O, Akyol O. A methodological approach to superoxide dismutase (SOD) activity assay based on inhibition of nitroblue tetrazolium (NBT) reduction. Clin Chim Acta. 1993;214(1):103-4.

66. Martinez-Garcia JF, Monte E, Quail PH. A simple, rapid and quantitative method for preparing Arabidopsis protein extracts for immunoblot analysis. Plant J. 1999;20(2):251-7.

67. Alexander RD, Morris PC. A proteomic analysis of 14-3-3 binding proteins from developing barley grains. Proteomics. 2006;6(6):1886-96.

68. Dou Y, Liu XG, Yin YJ, Han SP, Lu Y, Liu Y, et al. Affinity chromatography revealed insights into unique functionality of two 14-3-3 protein species in developing maize kernels. J Proteome. 2015;1 14:274-86.

69. Zhang ZY, Liu HH, Sun C, Ma QB, Bu HY, Chong K, et al. A C2H2 zinc-finger protein OsZFP213 interacts with OsMAPK3 to enhance salt tolerance in rice. J Plant Physiol. 2018;229:100-10.

70. Zhang D, Guo X, Xu Y, Li H, Ma L, Yao X, et al. OsCIPK7 point-mutation leads to conformation and kinase-activity change for sensing cold response. J Integr Plant Biol. 2019.

\section{Publisher's Note}

Springer Nature remains neutral with regard to jurisdictional claims in published maps and institutional affiliations.

Ready to submit your research? Choose BMC and benefit from:

- fast, convenient online submission

- thorough peer review by experienced researchers in your field

- rapid publication on acceptance

- support for research data, including large and complex data types

- gold Open Access which fosters wider collaboration and increased citations

- maximum visibility for your research: over $100 \mathrm{M}$ website views per year

At $\mathrm{BMC}$, research is always in progress.

Learn more biomedcentral.com/submissions 